\title{
Impact of intracellular hemin on N-type inactivation of voltage-gated $\mathrm{K}^{+}$channels
}

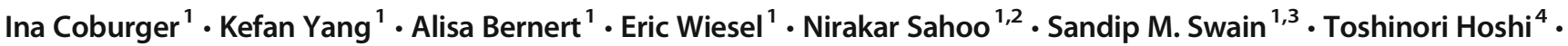 \\ Roland Schönherr ${ }^{1} \cdot$ Stefan H. Heinemann ${ }^{1}$ (D)
}

Received: 14 February 2020 / Revised: 20 March 2020 / Accepted: 28 April 2020 / Published online: 10 May 2020

(C) The Author(s) 2020

\begin{abstract}
$\mathrm{N}$-type inactivation of voltage-gated $\mathrm{K}^{+}$channels is conferred by the $\mathrm{N}$-terminal "ball" domains of select pore-forming $\alpha$ subunits or of auxiliary $\beta$ subunits, and influences electrical cellular excitability. Here, we show that hemin impairs inactivation of $\mathrm{K}^{+}$ channels formed by $\operatorname{Kv} 3.4 \alpha$ subunits as well as that induced by the subunits $\operatorname{Kv} \beta 1.1, \operatorname{Kv} \beta 1.2$, and $\operatorname{Kv} \beta 3.1$ when coexpressed with $\alpha$ subunits of the $\mathrm{Kv} 1$ subfamily. In $\mathrm{Kv} \beta 1.1$, hemin interacts with cysteine and histidine residues in the $\mathrm{N}$ terminus (C7 and $\mathrm{H} 10)$ with high affinity $\left(\mathrm{EC}_{50} 100 \mathrm{nM}\right)$. Similarly, rapid inactivation of Kv4.2 channels induced by the dipeptidyl peptidase-like protein DPP6a is also sensitive to hemin, and the DPP6a mutation C13S eliminates this dependence. The results suggest a common mechanism for a dynamic regulation of $\mathrm{Kv}$ channel inactivation by heme/hemin in $\mathrm{N}$-terminal ball domains of $\mathrm{Kv} \alpha$ and auxiliary $\beta$ subunits. Free intracellular heme therefore has the potential to regulate cellular excitability via modulation of $\mathrm{Kv}$ channel inactivation.
\end{abstract}

Keywords $\mathrm{K}^{+}$channel inactivation $\cdot$ A-type channel $\cdot \beta$ subunit $\cdot$ Hemin $\cdot$ Heme $\cdot$ Patch clamp

\section{Introduction}

All voltage-gated potassium $(\mathrm{Kv})$ channels share a similar overall structure with four $\alpha$ subunits, each consisting of six transmembrane helices and intracellular

Ina Coburger and Kefan Yang shared first authorship.

A Commentary to this article is available online at https://doi.org/10. 1007/s00424-020-02388-z

Electronic supplementary material The online version of this article (https://doi.org/10.1007/s00424-020-02386-1) contains supplementary material, which is available to authorized users.

Stefan H. Heinemann

Stefan.H.Heinemann@uni-jena.de

1 Department of Biophysics, Center for Molecular Biomedicine, Friedrich Schiller University Jena and Jena University Hospital, Hans-Knöll-Str. 2, D-07745 Jena, Germany

2 Department of Biology, The University of Texas Rio Grande Valley, 1201 West University Drive, Edinburg, TX 78539, USA

3 Present address: Department of Medicine, Duke University and Durham VA Medical Centers, Durham, NC 27710, USA

4 Department of Physiology, University of Pennsylvania, 415 Curie Boulevard, Philadelphia, PA 19104-6085, USA
$\mathrm{N}$ and $\mathrm{C}$ termini. $\mathrm{Kv}$ channels open similarly with membrane depolarization but markedly differ with respect to their inactivation properties. N-type or fast inactivation is found in A-type potassium channels and is due to a "ball-and-chain" mechanism involving the $\mathrm{N}$ terminus. Thereby, the $\mathrm{N}$ terminus acts as a "ball" structure and occludes the ion permeation pathway [11]. In excitable cells, $\mathrm{K}^{+}$channel inactivation regulates the shape of action potentials and the frequency of repetitive firing $[5,11]$. N-type inactivation is subject to modulation by various cell signaling processes. For example, reactive oxygen species [32], $\mathrm{pH}$ [26], hydrogen sulfide $\left(\mathrm{H}_{2} \mathrm{~S}\right)$ [39], $\mathrm{Ca}^{2+}$-dependent phosphorylation [31], and heme/hemin [34] regulate N-type inactivation of Kv1.4 channels, which are expressed in various cell types, such as smooth muscles, neurons, and cardiac myocytes $[3,7,35]$. Upregulation during cardiac hypertrophy and heart failure mark Kv1.4's clinical importance [15, 17, 22]. Kv3.4, another member of A-type channels, is present abundantly in skeletal muscles but also in mammalian neurons where it modulates action potential duration and repolarization rate [29]. "Delayed-rectifier" $\mathrm{Kv}$ channel subunits, including Kv1.1 and Kv1.5, lack an $\mathrm{N}$-terminal inactivation ball domain and by themselves 
undergo little or very slow inactivation $[12,19,24]$. However, such Kv1-containing channels do undergo fast $\mathrm{N}$-type inactivation when complexed with auxiliary cytoplasmic $\beta$ subunits $(\operatorname{Kv} \beta)[10,28]$. Their variable $\mathrm{N}$ terminal ball domains attached to the highly conserved core domain confer fast $\mathrm{N}(\beta)$-type inactivation once bound to Kv1 $\alpha$ subunits [28], thus greatly increasing the diversity of $\mathrm{Kv}$ channel inactivation phenotypes.

A phenomenon similar to $\mathrm{N}(\beta)$-type inactivation is observed in Kv4.2 channels: transmembrane dipeptidyl peptidase-like proteins, such as DPP6 and DPP10, function as $\beta$ subunits for $\mathrm{Kv} 4$ channels. Although their major protein part is located on the extracellular side, their $\mathrm{N}$ termini face the cytosol where they also induce fast channel inactivation $[1$, 21, 37].

Heme, Fe(II) protoporphyrin IX, is an essential cofactor in many hemoproteins and plays important roles in catalytic processes as well as in binding and transport of gases such as $\mathrm{O}_{2}$ $[6,25]$. In addition to this covalently bound form, free heme also interacts with proteins in a more dynamic manner by binding to heme-regulatory motifs (HRM) and thus functions as an intracellular signaling molecule [16]. Thereby, free or "labile" heme modulates the activity of diverse signal transducers and transcriptional regulators, such as the iron regulator regulatory protein (Irr), the heme activator protein (Hap1), and components of the Ras-MAPK signaling pathway [21]. By direct interaction with ion channels, heme may also have an impact on the cellular electrical excitability. For example, depending on the membrane voltage, heme and also the ferric hemin $\left(\mathrm{Fe}^{3+}\right.$-containing protoporphyrin IX) activate or inhibit the large-conductance voltage- and $\mathrm{Ca}^{2+}$-dependent potassium channel (Slo1 BK). A cytochrome-C-like CKACH motif in the $\mathrm{C}$ terminus constitutes one heme binding site [37]. In addition, heme impairs the fast N-type inactivation of Kv1.4 channels by binding to cysteine and histidine residues in the $\mathrm{N}$-terminal ball domain [34].

The presence of cysteine and histidine residues in the inactivation domains of other $\mathrm{Kv} \alpha$ subunits (Kv3.4) and some auxiliary $\beta$ subunits $(\operatorname{Kv} \beta 1.1, \operatorname{Kv} \beta 1.2$, Kvß3.1) (Suppl. Fig. 1) suggests that heme might be a more general modulator of $\mathrm{N}$-type and $\mathrm{N}(\beta)$-type inactivation. Here, we describe the impact of hemin on the inactivation induced by the $\mathrm{N}$ termini of Kv3.4 $\alpha$ subunits and the auxiliary $\beta$ subunits $\operatorname{Kv} \beta$ and DPP6a, acting on Kv1 and Kv4 channels, respectively. Sitedirected mutagenesis together with electrophysiology and microscale thermophoresis (MST) of recombinantly produced proteins demonstrate that $\mathrm{N}$-terminal cysteine and histidine residues take part in hemin coordination in the nanomolar concentration range. The results suggest a general mechanism of select A-type Kv channel modulation by heme or hemin with a potential influence on cellular excitability.

\section{Materials and methods}

\section{Chemicals}

Solutions were made of high-grade chemicals obtained from Sigma-Aldrich (Taufkirchen, Germany) and Carl Roth (Karlsruhe, Germany). Stock solutions $(1 \mathrm{mM})$ of hemin (Fe(III) protoporphyrin IX) and protoporphyrin IX (ppIX) were prepared daily by dissolving them in $30 \mathrm{mM} \mathrm{NaOH}$ for $30 \mathrm{~min}$ and were stored at $4{ }^{\circ} \mathrm{C}$ in the dark. Working solutions were diluted from $1 \mathrm{mM}$ stock in bath solution immediately before use.

\section{Channel constructs and mutagenesis}

The expression plasmids coding for Kv1.4 (Kcna4, P15385) and Kv3.4 from Rattus norvegicus (Kcnc4, Q63734) and mutants were cloned as described before [34, 39]. The expression plasmids encoding Kv1.5 (KCNA5, P22460), Kvß1.1, $\mathrm{Kv} \beta 1.2, \operatorname{Kv} \beta 1.3$ (KCNAB1, Q14722), Kvß3.1 (KCNAB3, O43448), and DPP6a from Homo sapiens and Kv1.1 (Kcna1, P10499) and Kv4.2 (Kcnd2, Q63881) from Rattus norvegicus were subcloned into pcDNA3.1. Accession numbers refer to the UniProt database. Mutations were generated using the QuikChange Site-Directed Mutagenesis Kit (Agilent, Waldbronn, Germany) or an overlap-extension mutagenesis approach [33].

For protein expression in Escherichia coli, the sequence coding for $\mathrm{hKv} \beta 1.1$ amino acids M1-K140 was subcloned into a modified pMALc2T vector with an N-terminal maltose-binding protein (MBP) followed by a (His) ${ }_{6}$-tag. Mutations were created using the QuikChange Site-Directed Mutagenesis Kit (Agilent) and verified by sequencing.

\section{Channel expression in HEK293t cells}

Human embryonic kidney 293t (HEK293t) cells (CAMR, Porton Down, Salisbury, UK) were cultured in medium composed of 45\% Dulbecco's minimal Eagle's medium (DMEM) and 45\% Ham's F-12 Nutrient Mixture, supplemented with $10 \%$ fetal bovine serum in a humid $37^{\circ} \mathrm{C}$ incubator with $5 \%$ $\mathrm{CO}_{2}$. When HEK293t cells were grown to $30-50 \%$ confluence, they were transiently transfected with plasmid coding for $\mathrm{Kv} \alpha$ subunits alone or with $\beta$ subunits using the Roti-Fect transfection kit (Carl Roth, Karlsruhe, Germany). The weight ratio between $\alpha$ and $\beta$ subunits DNA for transfection was 1:3. For visual identification of transfected cells, CD8 plasmid was cotransfected, and anti-CD8-coated Dynabeads (Deutsche Dynal GmbH, Hamburg, Germany) were used. Electrophysiological recordings were performed 1-2 days after transfection. 


\section{Channel expression in Xenopus oocytes}

Expression in Xenopus laevis oocytes and recording from inside-out patches is described in the Supplementary Material.

\section{Electrophysiological recordings}

Inside-out recordings were performed at room temperature $\left(20-24{ }^{\circ} \mathrm{C}\right)$ using an EPC-9 or EPC-10 patch-clamp amplifier operated by PatchMaster software (both HEKA Elektronik, Lambrecht, Germany). Patch pipettes were fabricated from borosilicate glass (GB150F-8P, Science Products, Hofheim, Germany) and were coated with dental wax (Patterson Dental, Mendota Heights, MN, USA) to reduce their capacitance. After firepolishing the pipettes, resistances of 0.9-2.5 $\mathrm{M} \Omega$ were obtained. An agar bridge connected the bath solution and the ground electrode. All voltages were corrected for the liquid junction potential. Leak and capacitive currents were corrected using a $\mathrm{p} / 6$ method. Depending on the kinetics of recovery from inactivation, test pulses of Kv1.4 and $\mathrm{Kv} 1.4 / \mathrm{Kv} \beta 1$ were typically applied every $60 \mathrm{~s}$, and every $15 \mathrm{~s}$ for Kv3.4 and Kv4.2.

The pipette solution composed of (in mM) $148 \mathrm{~N}$-methyl-d-glucamine (NMDG), $10 \mathrm{KCl}, 1 \mathrm{MgCl}_{2}, 1.5 \mathrm{CaCl}_{2}$, and 10 4-(2-hydroxyethyl)-1-piperazineethanesulfonic acid (HEPES), pH 7.9 with $\mathrm{HCl}$. Ten millimolar $\mathrm{K}^{+}$was used to minimize the impact of C-type inactivation $[19,27]$. The bath solution composed of (in $\mathrm{mM}$ ) $140 \mathrm{KCl}, 0.2$ reduced glutathione (GSH), 10 ethylene glycol tetraacetic acid (EGTA), and 10 HEPES, pH 7.9 with KOH. For Kv4.2 recordings, the pipette solution contained (in $\mathrm{mM}$ ) 146 $\mathrm{NaCl}, 4 \mathrm{KCl}, 2 \mathrm{MgCl}_{2}, 2 \mathrm{CaCl}_{2}, 0.2 \mathrm{GSH}$, and 10 HEPES, pH 7.4 with $\mathrm{NaOH}$.

\section{Expression and purification of $h K v \beta 1.1$}

$\mathrm{hKv} \beta 1.1$ comprising amino acids M1-K140 was expressed in Escherichia coli BL21 (DE3) pRIL. Cells were grown in TY medium at $22{ }^{\circ} \mathrm{C}$ to mid-log growth phase, induced with $0.5 \mathrm{mM}$ IPTG (isopropyl $\beta$-D-1-thiogalactopyranoside), and harvested after $20 \mathrm{~h}$ by centrifugation at $4000 \mathrm{~g}$ for $20 \mathrm{~min}$. Cells were resuspended in buffer A $(50 \mathrm{mM}$ Tris, $500 \mathrm{mM} \mathrm{NaCl}, 5 \mathrm{mM}$ DTT, $\mathrm{pH}$ 8.0) and lysed by sonification. The clear cell lysate was applied to a HisTrap FF crude affinity column (GE Healthcare), washed with buffer $\mathrm{A}+16 \mathrm{mM}$ imidazole, and eluted with buffer $\mathrm{A}+250 \mathrm{mM}$ imidazole. The protein was further purified using a SD200 10/300 Increase column (GE Healthcare) equilibrated with PBS, pH 7.4, $1 \mathrm{mM}$ TCEP (tetrachlorphenole).

\section{Microscale thermophoresis}

Microscale thermophoresis (MST) experiments were performed with the Monolith NT.115 (NanoTemper Technologies) in a buffer containing PBS, $2 \mathrm{mM} \mathrm{GSH}$, $\mathrm{pH}$ 7.4. Purified $\mathrm{hKv} \beta 1.11-140$ was labeled according to the manufacturer's instructions using the Labelling Kit Monolith NT RED-NHS (NanoTemper Technologies). A twofold dilution series of hemin ranging from $1.2 \mathrm{nM}$ to $40 \mu \mathrm{M}$ was mixed with labeled protein (final protein concentration: approximately $50 \mathrm{nM}$ ). To remove aggregates, each sample was centrifuged at 13,000 rpm for $5 \mathrm{~min}$ before filled into premium capillaries (NanoTemper Technologies).

\section{Data analysis and statistics}

Data were analyzed with FitMaster (HEKA Elektronik) and IgorPro (WaveMetrics, Lake Oswego, OR, USA). Data are presented as means \pm SEM with $n$ independent measurements.

\section{Results}

\section{Impact of hemin on Kv3.4 inactivation}

Kv1.4 channels undergo both $\mathrm{N}$ - and C-type inactivation. The fast $\mathrm{N}$-type inactivation is markedly slowed down by intracellular hemin, and molecular analysis revealed hemin binding to the N-terminal ball domain via interaction with cysteine and, to a lesser extent, histidine residues [34]. Since Kv3.4 channels undergo even faster N-type inactivation, which is also redox sensitive [39], we expressed Kv3.4 in HEK293t cells, measured voltage-activated currents in inside-out membrane patches, and applied hemin. As shown in Fig. 1a, Kv3.4 produced voltage-dependent $\mathrm{K}^{+}$currents with rapid inactivation properties with an inactivation time constant at $50 \mathrm{mV}$ of about $13 \mathrm{~ms}$, albeit variable among different cell batches. To avoid a confounding effect by oxidizing cysteines in the N-terminal inactivation domain, the intracellular solution contained $200 \mu \mathrm{M}$ reduced GSH. Under this condition, application of $200 \mathrm{nM}$ hemin in the intracellular solution considerably slowed down the inactivation of Kv3.4 channels with time constant of inactivation increasing from $12.0 \pm 0.1 \mathrm{~ms}$ (GSH control) to $23.8 \pm 0.5 \mathrm{~ms}$ ( $200 \mathrm{nM}$ hemin); the noninactivating current component increased from $5.2 \pm 0.1$ to $22.0 \pm 0.2 \%$. At $1 \mu \mathrm{M}$ hemin, inactivation was impaired even more $(28.6 \pm 0.2 \mathrm{~ms}$ and a non-inactivating component of $34.9 \pm 0.1 \%$ ), and even at $40 \mathrm{nM}$ hemin, there was a consistent slowing effect (Fig. 1a, b). The hemin effect at $200 \mathrm{nM}$ saturated after about $1.5 \mathrm{~min}$. Washout of the hemin for $2 \mathrm{~min}$ resulted in partial recovery; additional DTT application resulted in more complete recovery (Suppl. Fig. 2). Other than the aforementioned slow-down of inactivation, intracellular 
a

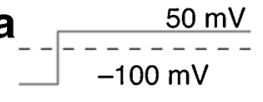

Hemin
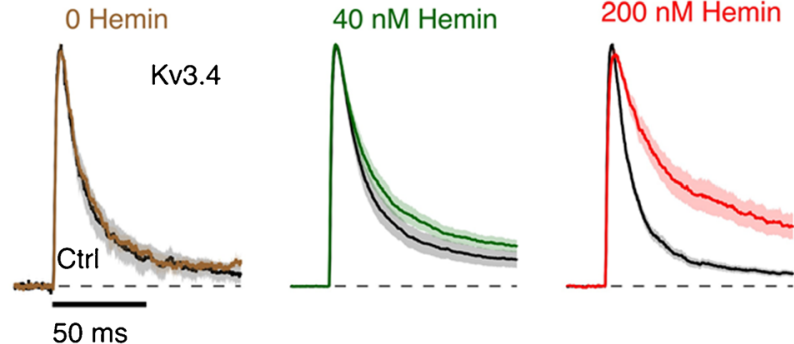

C

rKv1.4 MEVAMVSAESSGCNSHMPYGYAAQARARERERLAHSR ... rKv3.4

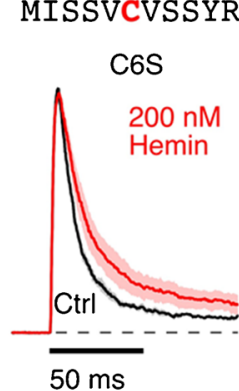

Fig. 1 Inactivation of Kv3.4 is impeded by hemin. a Mean inside-out patch-clamp current traces, normalized to the peak current, from HEK293t cells expressing Kv3.4 channels for depolarization steps to $50 \mathrm{mV}$ from a holding potential of $-100 \mathrm{mV}$ in solutions containing $200 \mu \mathrm{M}$ reduced GSH about 1 min after patch excision (Ctrl, black) and about $2 \mathrm{~min}$ after application of the same control solution (left) or solutions containing the indicated hemin concentration (color). Thick traces are mean values and shading indicates SEM. For $n$, see panel (b). b Mean non-inactivated current fraction at $50 \mathrm{~ms}$ after depolarization

hemin had no impact on the recovery from inactivation (Suppl. Fig. 3) and the peak current-voltage relationship (Suppl. Fig. 4). The peak current was only marginally affected (Suppl. Fig. 5). Protoporphyrin IX (ppIX), i.e., the ring structure without a central metal ion, even at $2 \mu \mathrm{M}$ neither slowed down inactivation nor inhibited the effect of $200 \mathrm{nM}$ hemin on Kv3.4 channel inactivation (Suppl. Fig. 6).

The $\mathrm{N}$ terminus of Kv3.4 harbors two cysteine residues (C6 and $\mathrm{C} 24$ ), which were previously shown to contribute to the channel's redox and hydrogen sulfide sensitivity [1, 32]. However, in contrast to Kv1.4, the Kv3.4 N terminus lacks histidine (Suppl. Fig. 1, Fig. 1c). Since cysteine residues often take part in heme coordination, we mutated them individually and together to serine (C6S, C24S, C6S:C24S) and examined the effect of $200 \mathrm{nM}$ hemin. For the single mutants, the impact of $200 \mathrm{nM}$ hemin was strongly diminished (Fig. 1c, d): the non-inactivated current fraction after $50 \mathrm{~ms}$ at $50 \mathrm{mV}$ decreased from 0.35 (WT) to less than 0.25 for both single mutants. The double mutant C6S:C24S was insensitive to hemin. In neither case, the peak currents were significantly affected (Suppl. Figs. 4, 5). These results suggest that both cysteine

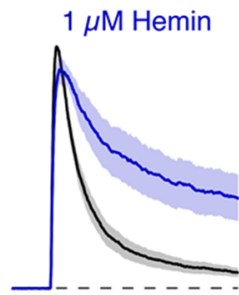

b

(6) (10) (11)

(10)

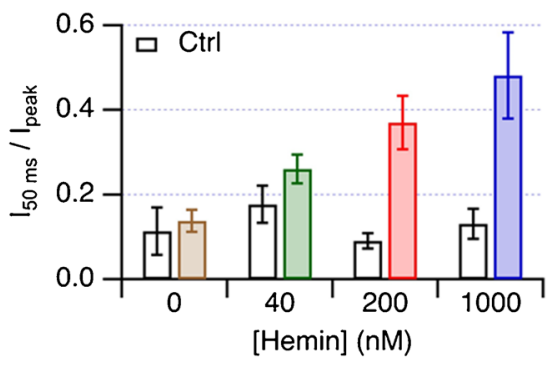

d $(11)$ (5)

(8)

(5)

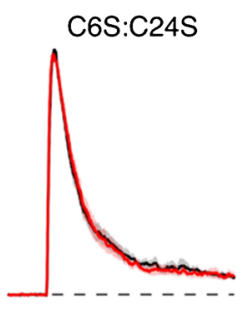

onset under control conditions (white bars) and for the indicated hemin concentrations (color). Data are means \pm SEM with $n$ in parentheses. c Alignment of the N-terminal protein sequences of (rat) rKv1.4 and rKv3.4 $\alpha$ subunits with Cys and His highlighted (top). Mean normalized current traces as in (a) for rKv3.4 mutants C6S, C24S and the combination C6S:C24S(SS) for application of $200 \mathrm{nM}$ hemin (bottom). d Mean non-inactivated current fraction for $200 \mathrm{nM}$ hemin application to the indicated mutants

residues in the $\mathrm{N}$-terminal ball domain contribute to hemin coordination, which subsequently impairs the $\mathrm{N}$ type inactivation process of Kv3.4 channels.

\section{Effect of hemin on Kvß1.1-induced inactivation}

$\mathrm{N}$ termini of some A-type potassium channels contain heme binding motifs. In addition, auxiliary subunits of the $\operatorname{Kv} \beta$ protein family harbor cysteines and histidines in their $\mathrm{N}$ termini (Suppl. Fig. 1), which potentially contribute to heme binding. The contribution of the $\operatorname{Kv} \beta 1$ subunit is most readily assessed by coexpression with a noninactivating Kv1 channel, such as Kv1.1. Expression of Kv1.1 in HEK293t cells, however, was not high enough to warrant inside-out macroscopic current patch-clamp measurements. Therefore, we coexpressed Kv1.1 together with $\mathrm{Kv} \beta 1.1$ in Xenopus oocytes and measured $\mathrm{K}^{+}$currents in inside-out macro patches. Expression of Kv1.1 alone without $\operatorname{Kv} \beta 1.1$ resulted in non-inactivation currents after depolarization to $40 \mathrm{mV}$, and intracellular application of $200 \mathrm{nM}$ hemin did not affect the current signal (Suppl. Fig. 7, top). When coexpressed with $\operatorname{Kv} \beta 1.1$, the channel inactivated rapidly, and this inactivation was abolished 
after the application of $200 \mathrm{nM}$ hemin (Suppl. Fig. 7). $\mathrm{Kv} \beta 1.1$ harbors a ${ }_{7} \mathrm{CxxH}_{10}$ heme recognition site in the $\mathrm{N}$-terminal ball domain similar to Kv1.4 (Suppl. Fig. 1). Mutagenesis of C7S and H10A in isolation resulted in a clearly diminished effect of hemin on inactivation, and only concurrent double mutation (C7S:H10A) rendered the $\operatorname{Kv} \beta 1.1$-induced inactivation of Kv1.1 channels insensitive to $200 \mathrm{nM}$ hemin (Suppl. Fig. 7, bottom).

To better compare with the results obtained for $\mathrm{Kv} 3.4$, we also studied heme-Kv $\beta$ interaction in HEK293t cells. To yield large enough currents, we expressed Kv1.4 channels alone and in combination with $\operatorname{Kv} \beta 1.1$ subunits and mutants (Fig. 2). As we showed previously [34], N-type inactivation of Kv1.4 is sensitive to intracellular hemin. However, at high $\mathrm{pH}$, this N-type inactivation kinetics is too slow to be discerned from residual C-type inactivation [26, 39]. Therefore, when measuring at $\mathrm{pH} 7.9$, the Kv1.4 currents recorded in inside-out patches exhibit slow inactivation that is insensitive to intracellular hemin application (Fig. 2a). In addition, basic $\mathrm{pH}$ increases the solubility of hemin. When coexpressed with $\operatorname{Kv} \beta 1.1$, however, the inactivation time course was much accelerated and became sensitive to hemin. Hemin at $200 \mathrm{nM}$ clearly slowed down inactivation at $50 \mathrm{mV}$, and even at $40 \mathrm{nM}$, some slowing was observed (Fig. 2a, b). The single mutation $\mathrm{C} 7 \mathrm{~S}$ and the double mutation C7S:H10A in Kvß1.1 rendered the Kv1.4 complexes insensitive to $500 \mathrm{nM}$ hemin (Fig. 2c). Only for hemin-sensitive channel complexes intracellular hemin application slightly increased the peak current as expected for partial removal of inactivation (Suppl. Fig. 8).
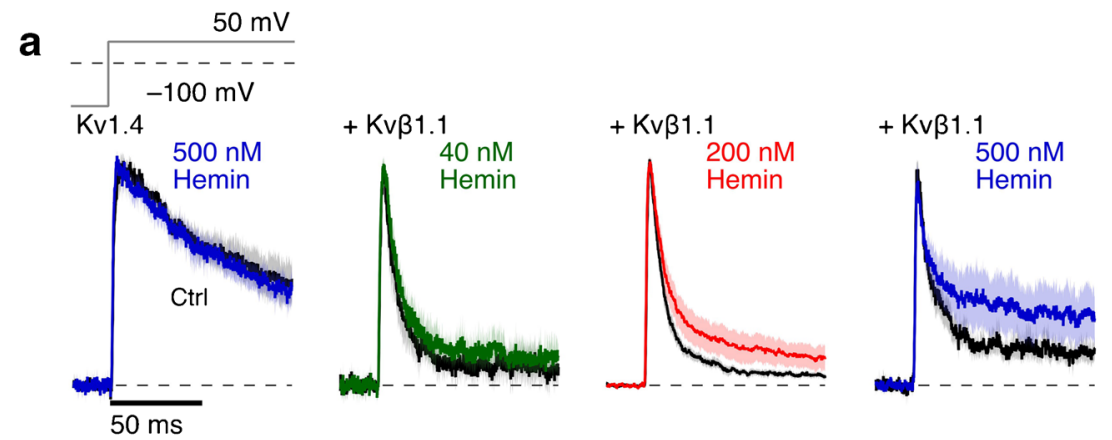

b

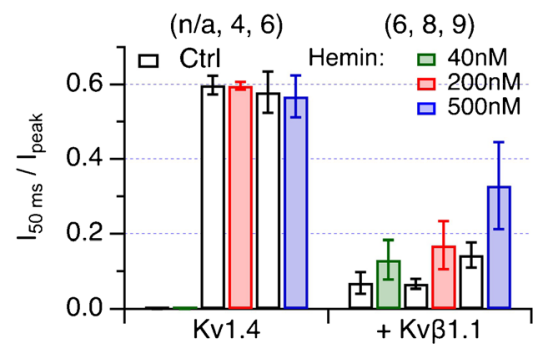

C MQVSIACTEHNLKSRNGEDRLLSK

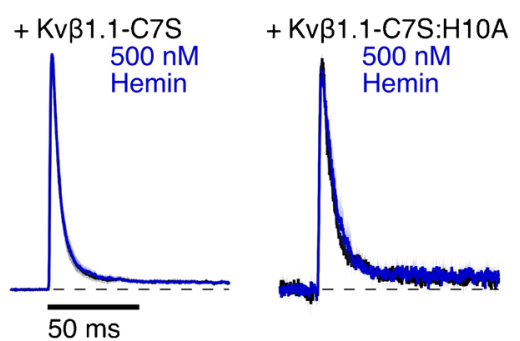

\section{d}

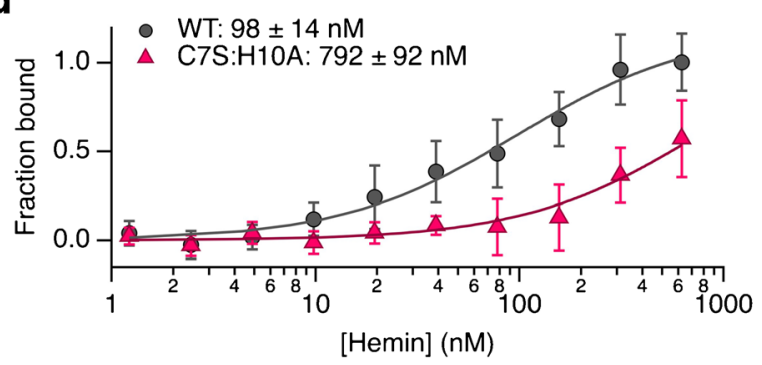

Fig. 2 Heme sensitivity of $\operatorname{Kv} \beta 1.1$-mediated inactivation. a Mean normalized inside-out patch-clamp current traces from HEK293t cells expressing Kv1.4 channels alone (left) or with coexpression of $\mathrm{Kv} \beta 1.1$ by depolarization steps to $50 \mathrm{mV}$ from a holding potential of $-100 \mathrm{mV}$. Thick black traces are means before, and the colored traces about 2 min after application of the indicated concentrations of hemin. All solutions additionally contained $200 \mu \mathrm{M}$ GSH. Shading indicates SEM. For $n$, see panel (b). b Fraction of non-inactivated current after $50 \mathrm{~ms}$ depolarization for Kv1.4 and with coexpression of $\operatorname{Kv} \beta 1.1$. Data are means $\pm \mathrm{SEM}, n$ in

parentheses. c N-terminal protein sequence of $\operatorname{Kv} \beta 1.1$ (top). Current traces as in (a) for $\mathrm{Kv} \beta 1.1$ mutants C7S and C7S:H10A (bottom). Measurements were performed at $\mathrm{pH} 7.9$ to eliminate $\mathrm{N}$-type inactivation endogenous to Kv1.4. d Microscale thermophoresis of the Kvß1.1 Nterminal domain. Binding curves for interaction of $\mathrm{Kv} \beta 1.11-140$ fused to MBP (gray circles) and mutant C7S:H10A (magenta triangles) as a function of hemin concentration, normalized to the WT data at the highest concentration of hemin. Data are means $\pm \operatorname{SEM}(n=3 ; 2$ protein preparations) 


\section{Hemin binds with high affinity to Kvß1.1}

To confirm the physical interaction of hemin with the $\mathrm{N}$ terminus of $\operatorname{Kv} \beta 1.1$ suggested by the electrophysiological results, microscale thermophoresis was used to evaluate the binding strength of hemin to the recombinant $\mathrm{Kv} \beta 1.1$ 1-140 protein fused to MBP-(His) $)_{6}$. Titration with hemin against labeled $h K v \beta 1.1 \quad 1-140$ fused to MBP-(His) ${ }_{6}$ induced clear temperature-dependent changes in fluorescence (Fig. 2d). Determination of the binding affinity revealed a binding constant of $98 \pm 14 \mathrm{nM}$ (Fig. 2d). Performing the same analysis for protein mutant C7S:H10A showed no binding signal up to about $100 \mathrm{nM}$ hemin. Since the maximally accessible hemin concentration is limited by progressive fluorescence quenching, experiments with MST are restricted to about $600 \mathrm{nM}$ hemin, thus precluding the determination of saturation for the mutant. With a data fit constrained to the maximally obtainable MST signal, we thus estimated a hemin binding constant to the mutant to be $792 \pm 92 \mathrm{nM}$ (Fig. 2d). It should be noted that this is a lower limit and may also reflect unspecific binding to the protein.

\section{Splice variants of Kvß1 subunits}

The splice variants $\operatorname{Kv} \beta 1.1-\operatorname{Kv} \beta 1.3$ differ in their N-terminal inactivation domains. While $\mathrm{Kv} \beta 1.1$ harbors the hemeregulatory motif ${ }_{7} \mathrm{CxxH}_{10}$ in the distal ball domain, $\mathrm{Kv} \beta 1.2$ exhibits a similar motif $\left({ }_{28} \mathrm{CxxH}_{31}\right)$ in the "chain" domain. In addition, the $\mathrm{N}$-terminal ball domain of $\mathrm{Kv} \beta 1.2$ contains a histidine and a cysteine that are separated by five residues ${ }_{2} \mathrm{H} \ldots \mathrm{C}_{8}$, Fig. 3a). The $\mathrm{N}$ terminus of $\mathrm{Kv} \beta 1.3$ does not harbor cysteine or histidine (Fig. 3a). We thus examined heme dependence of inactivation induced by $\operatorname{Kv} \beta 1.2$ and $\operatorname{Kv} \beta 1.3$ when coexpressed with Kv1.4 in HEK293t cells. In this combination, however, $\operatorname{Kv} \beta 1.2$ only resulted in a marginal acceleration of Kv1.4 inactivation. Application of $500 \mathrm{nM}$ intracellular hemin slowed down inactivation further to a level of Kv1.4 channels alone (Fig. 3b, c, left). Coexpression of Kv1.4 with $\mathrm{Kv} \beta 1.3$ results in somewhat faster inactivation, and its time course was unaffected by $500 \mathrm{nM}$ hemin (Fig. 3b, c, center). Coexpression of Kv1.5 and Kv $\beta 1.3$ in Xenopus oocytes and application of $200 \mathrm{nM}$ hemin to inside-out patches revealed that hemin neither affects Kv1.5 channels alone or N-type inactivation induced by $\operatorname{Kv} \beta 1.3$ (Suppl. Fig. 9). Coexpression of $\operatorname{Kv} \beta 3.1$, which harbors two cysteine residues in the $\mathrm{N}$-terminal domain (Fig. 3a), with Kv1.4 also results in faster inactivation than Kv1.4 alone, and $500 \mathrm{nM}$ hemin slowed down inactivation (Fig. $3 \mathrm{~b}, \mathrm{c}$, right). In general, the impact of hemin on the inactivation of $\operatorname{Kv} \beta$-mediated inactivation appeared weaker than that on $\mathrm{N}$-type inactivation of Kv3.4. a

Kvß1.1 -MQVSIACTEHN-----LKSRNGEDRLLSKQSST Kvß1.2 MHLYKPACADIPSPKLGLPKSSESALKCRWHLAV Kvß1.3 MLAARTGAAGSQISEENTKLRRQSGFSVAGKDKS Kvß3.1 -MQVSIACTEQN---LRSRSS--DERLCGPRPGP

b

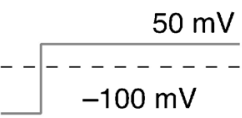

$\mathrm{Kv} 1.4+\mathrm{Kv} \beta 1.2$
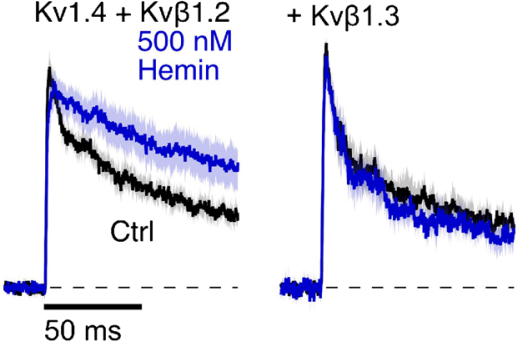

$+\mathrm{Kv} \beta 3.1$

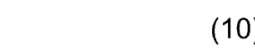

(10)

(6)
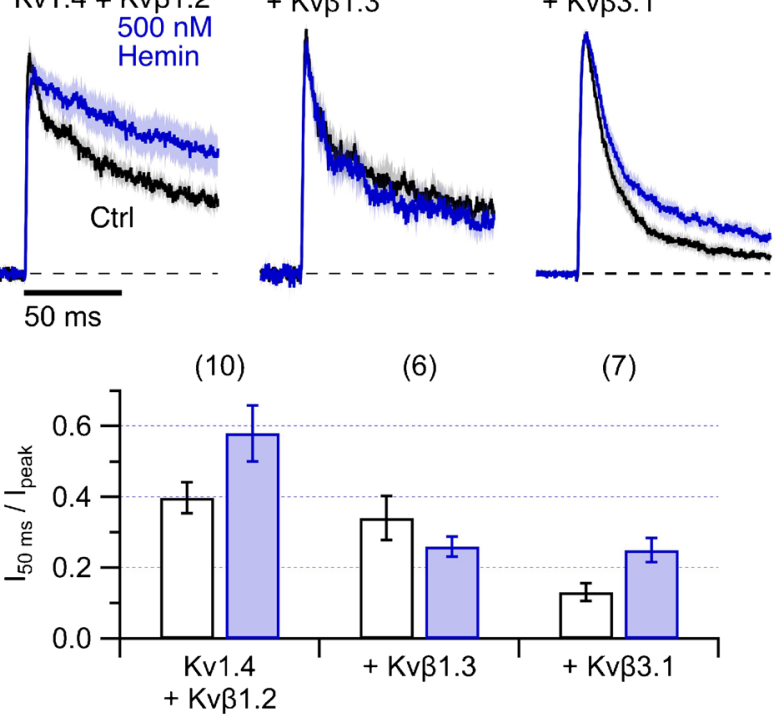

Fig. $3 \mathrm{Kv} 1.4$ coexpression with $\operatorname{Kv} \beta 1.2, \operatorname{Kv} \beta 1.3$, and $\operatorname{Kv} \beta 3.1$. a Nterminal protein sequence alignment of the $\operatorname{Kv} \beta 1$ splice variants and Kv $\beta 3.1$. b Mean normalized inside-out patch-clamp current traces from HEK293t cells expressing Kv1.4 channels with $\operatorname{Kv} \beta 1.2$ (left), $\operatorname{Kv} \beta 1.3$ (center), or $\mathrm{Kv} \beta 3.1$ (right) by depolarization steps to $50 \mathrm{mV}$ from a holding potential of $-100 \mathrm{mV}$. Thick black traces are means before and the colored traces about 2 min after application of $500 \mathrm{nM}$ hemin (blue). All solutions additionally contained $200 \mu \mathrm{M}$ GSH. Shading indicates SEM. For $n$, see panel (c). Measurements were performed at $\mathrm{pH} 7.9$ to eliminate N-type inactivation endogenous to Kv1.4. $\mathbf{c}$ Fraction of noninactivated current after $50 \mathrm{~ms}$ depolarization for Kv1.4 with coexpression of the indicated $\operatorname{Kv} \beta$ subunits. Data are means \pm SEM, $n$ in parentheses

\section{Fast inactivation of Kv4.2 channels}

$\mathrm{K}^{+}$channels of the Kv4 family also exhibit rapid inactivation, which is further accelerated by coassembly with transmembrane dipeptidyl peptidase-like proteins, such as DPP6 or DPP10. The $\mathrm{N}$ terminus of these single-pass transmembrane proteins reaches the cytosolic face to function as inactivation accelerator [13]. Since the N-terminal sequences of DPP6a and DPP10a contain cysteine and histidine residues that may potentially coordinate heme (e.g., Fig. 4a, top), we investigated Kv4.2 channels in HEK293t cells alone and coexpressed with DPP6a. When recorded in the whole-cell configuration, extracellular application of $5 \mu \mathrm{M}$ hemin did not affect the current amplitude or the time course of inactivation $(n=5$, data not shown). In the inside-out patch-clamp configuration, however, application of $200 \mathrm{nM}$ hemin under reducing conditions eliminated the rapid inactivation induced by DPP6a to a 
a

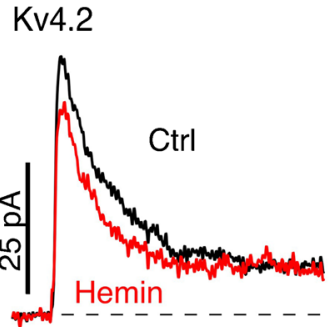

b

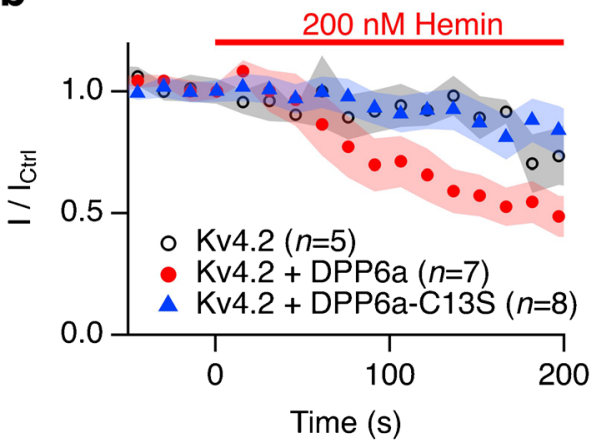

Fig. 4 Impact of hemin on inactivation induced by DPP6a. a Representative inside-out current recordings from HEK293t cells expressing Kv4.2 alone (left) or together with human DPP6a (center) or its mutant C13S (right). Currents were measured at $60 \mathrm{mV}$ before (black) and $200 \mathrm{~s}$ after application of $200 \mathrm{nM}$ hemin in the presence of $200 \mu \mathrm{M}$ reduced GSH (red). The green trace in the center panel is the

level approximately corresponding to the inactivation seen with Kv4.2 alone (Fig. 4a, left, center). In addition, hemin application $(200 \mathrm{nM})$ reduced the peak current amplitude to about 50\% (Fig. 4b). Mutagenesis of DPP6a to eliminate the N-terminal cysteine (DPP6a-C13S) abolished both effects: Kv4.2 + DPP6a-C13S currents were insensitive to $200 \mathrm{nM}$ hemin, both with respect to peak amplitude and time course of inactivation (Fig. 4).

\section{Discussion}

$\mathrm{N}$-type inactivation is a major characteristic of A-type potassium channels and can be modulated by several physiological factors $[4,6,25,32,39]$. In this study, we showed that fast inactivation of Kv3.4 is slowed by hemin in a probable physiologically relevant concentration range. Mutagenesis revealed that the cysteine residues $\mathrm{C} 6$ and $\mathrm{C} 24$ in the Nterminal ball domain are important for the heme dependence. Only mutagenesis of both cysteines to serine completely rendered fast N-type inactivation resistant to hemin (Fig. 1). $\mathrm{Kv} 3.4$ is widely expressed in the mammalian nervous system and regulates the repolarization of action potentials and thus its duration $[18,29,30]$. Slowing of inactivation by heme may, therefore, result in shorter and fewer action potentials, thus
MNQTAGVSNSVRCPPGKGHK . .

Kv4.2 + DPP6a-C13S

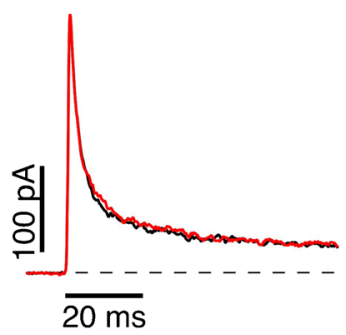

C

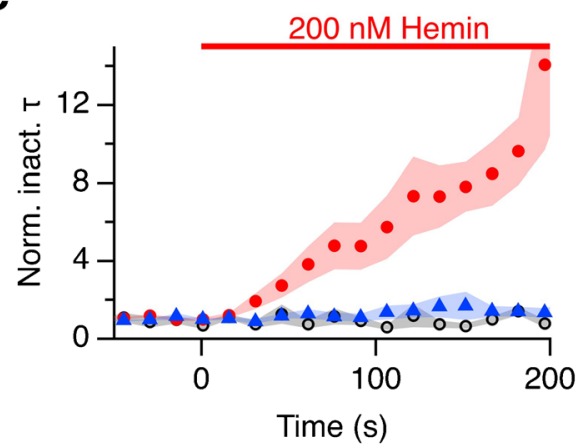

trace with hemin but scaled in amplitude to match the peak current of the control. The N-terminal sequence of human DPP6a is shown at the top. $\mathbf{b}$ Time course of the peak currents for the indicated constructs and hemin application. $\mathbf{c}$ Time constants of fast inactivation, normalized to the control values before hemin application. Symbol use and $n$ as in (b). Data in (b) and (c) are means \pm SEM with $n$ indicated in (b)

affecting electrical excitability of neurons. In a synapse, the changes in action potential duration may influence $\mathrm{Ca}^{2+}$-dependent neurotransmission. For example, in dorsal root ganglia (DRG) cells containing Kv1.4 and Kv3.4 channels, a physiological consequence would be an attenuation of pain signaling $[8,36]$.

The same reasoning may be applied to Kv1.4 channels in DRG cells. As we showed previously [34], heme also impairs N-type inactivation Kv1.4 channels. In this case, C13 and H16 take part in coordinating heme to affect the structure of the inactivating ball-and-chain domain [34]. Interestingly, the Nterminal inactivation domains of Kv3.4 and Kv1.4 exhibit no structural similarity. While the inactivation peptide of Kv3.4 exhibits a four-leaf clover-like structure [1], Kv1.4 harbors a flexible inactivation domain anchored at a five-turn helix [38]. Perhaps, specific sequence motifs are not required for hemepeptide interactions. Here, we identified cysteine residues in Kv3.4 to contribute to heme coordination (Fig. 1). It should be noted, though, that other residues, for example Tyr10, may be involved in stabilizing a heme-peptide complex.

Cysteine residues were identified to be important in the impact of hemin on Kv3.4 inactivation. The effect of hemin may also be mediated by coordination of heme/hemin by the inactivating peptide or potentially by redox processes involving $\mathrm{C} 6$ and $\mathrm{C} 24$. We tried to limit a potential redox process by 
performing the experiments in the presence of a 1000-fold excess of reduced glutathione; however, we cannot entirely exclude the possibility that the named cysteine residues undergo some chemical modification in the presence of ferric hemin.

Based on the results with Kv1.4 and Kv3.4, heme might also be a regulator of $\mathrm{N}(\beta)$-type inactivation. Indeed, while elevated intracellular hemin was without effect on delayed rectifier Kv channels formed by Kv1.1 $\alpha$ subunits, inactivation induced by coexpression of $\operatorname{Kv} \beta 1.1$ was readily impaired by hemin (Suppl. Fig. 7). The same was true for the Kvß1.1induced fast inactivation of Kv1.4 channels (Fig. 2). In the latter case, we took advantage of the $\mathrm{pH}$ dependence of the N-type inactivation endogenous to Kv1.4: at pH 7.9, Kv1.4 Ntype inactivation is so slow such that it cannot be discriminated from $\mathrm{C}$-type inactivation anymore, while inactivation due to $\mathrm{Kv} \beta 1.1$ persists. Elimination of the potential hemeregulatory motif ${ }_{7} \mathrm{CxxH}_{10}$ in the ball domain of $\mathrm{Kv} \beta 1.1$ rendered the inactivation resistant to hemin. Individual mutation of the cysteine and histidine in this motif furthermore revealed that both sites contribute, and only full elimination of the motif abolished the hemin effect completely. This situation is similar to what was found for Kv1.4 channels with its N-terminal HRM ${ }_{13} \mathrm{CxxH}_{16}$ [34]. Investigating the mobility of Nterminal protein fragments of $\operatorname{Kv} \beta 1.1$ (residues 1-140) as a function of hemin concentration using an MST assay, we found evidence for the physical binding of hemin to this protein with an apparent binding constant of about $100 \mathrm{nM}$. No such binding was visible in peptides without an HRM (Fig. 2d). Besides inference about hemin binding to the peptide, the MST results also suggest that the heme-protein complex has a different thermophoretic mobility than the free components, arguing for heme-induced protein conformational changes. Using an array of other physical binding assays and molecular docking, we previously also concluded for the $\mathrm{N}$ terminus of Kv1.4 that heme may induce some structure to the intrinsically disordered protein fragment, which interferes with the required flexibility for inducing $\mathrm{N}$-type inactivation [34].

Functional evaluation of the splice variants $\operatorname{Kv} \beta 1.2$ and $\mathrm{Kv} \beta 1.3$ in inside-out patches from mammalian cells is compromised by the fact that they do not speed up inactivation of Kv1.4 as much as $\operatorname{Kv} \beta 1.1$. Nevertheless, the results obtained (Fig. 3, Suppl. Fig. 9) are consistent with the overall notion that cysteine and/or histidine residues take part in mediating the heme dependence of $\mathrm{N}(\beta)$-type inactivation. $\mathrm{Kv} \beta 1.3$ lacks $\mathrm{N}$-terminal cysteine or histidine resides and its inactivation is not affected by intracellular hemin $\mathrm{Kv} \beta 1.2$ harbors even two potential HRMs and, hence, hemin eliminates $\operatorname{Kv} \beta 1.2$-induced inactivation. The same is true for $\operatorname{Kv} \beta 3.1$ with two cysteine residues in the $\mathrm{N}$-terminal domain. On the other hand, $\mathrm{Kv} \beta 2.1$ which lacks the inactivation peptide and critical heme coordinating amino acids in the $\mathrm{N}$ terminus should be not affected by heme.

The rapid inactivation induced by the dipeptidyl peptidase-like protein DPP6a to Kv4.2 channels is also sensitive to intracellular heme, while the inactivation endogenous to Kv4.2 channels is insensitive (Fig. 4). Again, a cysteine residue in the $\mathrm{N}$-terminal part of DPP6a $(\mathrm{C} 13)$ is involved. This cysteine is part of a so-called CP motif and, together with a histidine five residues downstream, may form a novel hemecoordination site $\left({ }_{13} \mathrm{CPPGKGH}_{19}\right)$. The potentially heme-ligating cysteine and histidine enclose proline and glycine for maximal flexibility to even allow for hexacoordinated heme binding. Although the exact mechanism of how DPP6a induces inactivation of Kv4.2 channels is still elusive, the existence of HRMs in the $\mathrm{N}$ terminus of DPP6a and the dependence on intracellular heme suggests at least some similarity to $\mathrm{Kv} \beta$ subunits.

Slow-down or elimination of fast $\mathrm{K}^{+}$channel inactivation by elevated intracellular free heme may impair spike broadening regulation, potentially influencing neuronal excitability and learning $[9,14]$. Furthermore, heme deficiency observed in aging and Alzheimer's disease [2] may influence the inactivation phenotype in the opposite direction.

Inactivation characteristics of mammalian $\mathrm{Kv}$ channel complexes vary markedly. Some $\mathrm{Kv} \alpha$ subunits contain $\mathrm{N}$-terminal inactivation domains with HRMs conferring heme sensitivity to their fast inactivation. Other delayed rectifier-type $\alpha$ subunits lack their own inactivation domains but assembly with select $\operatorname{Kv} \beta$ subunits with HRMs may confer heme-sensitive N-type inactivation. Possibly, directed expression of $\operatorname{Kv} \beta 1.1, \operatorname{Kv} \beta 1.2$, or $\operatorname{Kv} \beta 3.1$ on the one hand or $\operatorname{Kv} \beta 1.3$ on the other generates inactivating $\mathrm{K}^{+}$channels dependent or independent, respectively, of redox conditions and heme concentration.

The physiological or pathophysiological conditions under which cytosolic free heme concentrations are altered strongly enough to have an influence on $\mathrm{K}^{+}$channel function, however, remain to be elucidated. The heme dependence of Kv3.4 and $\mathrm{Kv} 1.4+\mathrm{Kv} \beta 1.1$ and $\mathrm{Kv} 1.1+\mathrm{Kv} \beta 1.1$ complexes below $100 \mathrm{nM}$ suggests that the binding properties are in a range that are discussed to be relevant to the modulation of the hemedependent transcription repressor Bach1 [23]. Episodes of high heme concentrations such as in a trauma situation or after hemorrhagic insults may also affect electrical signaling by modulating the function of A-type channels. However, the exact physiological and/or pathophysiological significance is yet to be established, which requires quantitative assessments of free heme concentrations in live cells under different conditions. It is conceivable to utilize the heme binding sites at Ntype inactivating channels as pharmacological targets to deliberately affect the speed of $\mathrm{K}^{+}$channel inactivation, such as 
demonstrated for low-molecular weight $\mathrm{K}^{+}$channel disinactivators [20].

Our results show that N-type inactivation mediated by cysteine/histidine containing N-terminal protein parts of Atype potassium channel $\alpha$ and auxiliary $\beta$ subunits is impeded by hemin. The absence of sequence homology in the Nterminal binding regions suggests a general mechanism for heme-mediated modulation of A-type channel inactivation and, hence, of heme influencing electrical excitability.

Acknowledgments Open Access funding provided by Projekt DEAL. We thank Prof. Dr. P. Zipfel and A. Hartmann (Jena) for help with Microscale Thermophoresis, Dr. P. Hortschansky (Jena) for providing the modified expression vector pMALc2T, and E. Distler for control recordings on Kv4.2 channels.

Funding information This work was supported by grants of the German Research Foundation (FOR 1738: HE2993/12-2 and HE2993/18-1). T.H. was supported in part by the National Institutes of Health grant GM121375.

\section{Compliance with ethical standards}

Conflict of interest The authors declare that they have no conflict of interest.

Ethical approval All procedures performed in studies involving animals were in accordance with the ethical standards of the institution or practice at which the studies were conducted. This article does not contain any studies with human participants performed by any of the authors.

Informed consent Not applicable.

Abbreviations DTT, Dithiothreitol; DPP, Dipeptidyl peptidase-like protein; DRG, Dorsal root ganglia; GSH, Glutathione; HRM, Heme-regulatory motif; Kv channel, Voltage-gated potassium channel; MBP, Maltosebinding protein; MST, Microscale thermophoresis; ppIX, Protoporphyrin IX; WT, Wild type

Open Access This article is licensed under a Creative Commons Attribution 4.0 International License, which permits use, sharing, adaptation, distribution and reproduction in any medium or format, as long as you give appropriate credit to the original author(s) and the source, provide a link to the Creative Commons licence, and indicate if changes were made. The images or other third party material in this article are included in the article's Creative Commons licence, unless indicated otherwise in a credit line to the material. If material is not included in the article's Creative Commons licence and your intended use is not permitted by statutory regulation or exceeds the permitted use, you will need to obtain permission directly from the copyright holder. To view a copy of this licence, visit http://creativecommons.org/licenses/by/4.0/.

\section{References}

1. Antz C, Geyer M, Fakler B, Schott MK, Guy HR, Frank R, Ruppersberg JP, Kalbitzer HR (1997) NMR structure of inactivation gates from mammalian voltage-dependent potassium channels. Nature 385:272-275. https://doi.org/10.1038/385272a0
2. Atamna H, Killilea DW, Killilea AN, Ames BN (2002) Heme deficiency may be a factor in the mitochondrial and neuronal decay of aging. Proc Natl Acad Sci U S A 99:14807-14812. https://doi.org/ 10.1073/pnas.192585799

3. Barry DM, Trimmer JS, Merlie JP, Nerbonne JM (1995) Differential expression of voltage-gated $\mathrm{K}^{+}$channel subunits in adult rat heart. Relation to functional $\mathrm{K}^{+}$channels? Circ Res 77: 361-369. https://doi.org/10.1161/01.res.77.2.361

4. Beck EJ, Sorensen RG, Slater SJ, Covarrubias M (1998) Interactions between multiple phosphorylation sites in the inactivation particle of a $\mathrm{K}^{+}$channel. Insights into the molecular mechanism of protein kinase C action. J Gen Physiol 112:71-84. https:// doi.org/10.1085/jgp.112.1.71

5. Cai SQ, Li W, Sesti F (2007) Multiple modes of A-type potassium current regulation. Curr Pharm Des 13:3178-3184

6. Covarrubias M, Wei A, Salkoff L, Vyas TB (1994) Elimination of rapid potassium channel inactivation by phosphorylation of the inactivation gate. Neuron 13:1403-1412

7. Dixon JE, McKinnon D (1994) Quantitative analysis of potassium channel mRNA expression in atrial and ventricular muscle of rats. Circ Res 75:252-260. https://doi.org/10.1161/01.res.75.2.252

8. Ems T, Huecker MR (2019) Biochemistry, iron absorption. In: StatPearls. Treasure Island (FL)

9. Giese KP, Storm JF, Reuter D, Fedorov NB, Shao LR, Leicher T, Pongs O, Silva AJ (1998) Reduced $\mathrm{K}^{+}$channel inactivation, spike broadening, and after-hyperpolarization in $\mathrm{Kv} \beta 1.1$-deficient mice with impaired learning. Learn Mem 5:257-273

10. Heinemann SH, Rettig J, Graack HR, Pongs O (1996) Functional characterization of $\mathrm{Kv}$ channel $\beta$-subunits from rat brain. J Physiol 493(Pt 3):625-633. https://doi.org/10.1113/jphysiol.1996. $\mathrm{sp} 021409$

11. Hoshi T, Zagotta WN, Aldrich RW (1990) Biophysical and molecular mechanisms of Shaker potassium channel inactivation. Science 250:533-538. https://doi.org/10.1126/science.2122519

12. Hoshi T, Zagotta WN, Aldrich RW (1991) Two types of inactivation in Shaker $\mathrm{K}^{+}$channels: effects of alterations in the carboxyterminal region. Neuron 7:547-556

13. Jerng HH, Pfaffinger PJ (2014) Modulatory mechanisms and multiple functions of somatodendritic A-type $\mathrm{K}^{+}$channel auxiliary subunits. Front Cell Neurosci 8:82. https://doi.org/10.3389/fncel.2014. 00082

14. Jow F, Zhang ZH, Kopsco DC, Carroll KC, Wang K (2004) Functional coupling of intracellular calcium and inactivation of voltage-gated Kv1.1/Kvbeta1.1 A-type $\mathrm{K}^{+}$channels. Proc Natl Acad Sci U S A 101:15535-15540. https://doi.org/10.1073/pnas. 0402081101

15. Kaprielian R, Wickenden AD, Kassiri Z, Parker TG, Liu PP, Backx PH (1999) Relationship between $\mathrm{K}^{+}$channel down-regulation and $\left[\mathrm{Ca}^{2+}\right]_{\mathrm{i}}$ in rat ventricular myocytes following myocardial infarction. J Physiol 517:229-245. https://doi.org/10.1111/j.1469-7793.1999. 0229z.x

16. Kühl T, Imhof D (2014) Regulatory Fe(II/III) heme: the reconstruction of a molecule's biography. Chembiochem 15:2024-2035. https://doi.org/10.1002/cbic.201402218

17. Lee JK, Nishiyama A, Kambe F, Seo H, Takeuchi S, Kamiya K, Kodama I, Toyama J (1999) Downregulation of voltage-gated $\mathrm{K}^{+}$ channels in rat heart with right ventricular hypertrophy. Am J Phys 277:H1725-H1731. https://oi.org/10.1152/ajpheart.1999.277.5. H1725

18. Liu PW, Blair NT, Bean BP (2017) Action potential broadening in capsaicin-sensitive DRG neurons from frequency-dependent reduction of Kv3 current. J Neurosci 37:9705-9714. https://doi.org/10. 1523/jneurosci.1703-17.2017

19. Lopez-Barneo J, Hoshi T, Heinemann SH, Aldrich RW (1993) Effects of external cations and mutations in the pore region on $\mathrm{C}$ - 
type inactivation of Shaker potassium channels. Receptors Channels 1:61-71

20. Lu Q, Peevey J, Jow F, Monaghan MM, Mendoza G, Zhang H, Wu J, Kim CY, Bicksler J, Greenblatt L, Lin SS, Childers W, Bowlby MR (2008) Disruption of Kv1.1 N-type inactivation by novel small molecule inhibitors (disinactivators). Bioorg Med Chem 16:30673075. https://doi.org/10.1016/j.bmc.2007.12.031

21. Mense SM, Zhang L (2006) Heme: a versatile signaling molecule controlling the activities of diverse regulators ranging from transcription factors to MAP kinases. Cell Res 16:681-692. https:// doi.org/10.1038/sj.cr.7310086

22. Nishiyama A, Ishii DN, Backx PH, Pulford BE, Birks BR, Tamkun MM (2001) Altered $\mathrm{K}^{+}$channel gene expression in diabetic rat ventricle: isoform switching between Kv4.2 and Kv1.4. Am J Physiol Heart Circ Physiol 281:H1800-H1807. https://doi.org/10. 1152/ajpheart.2001.281.4.H1800

23. Ogawa K, Sun J, Taketani S, Nakajima O, Nishitani C, Sassa S, Hayashi N, Yamamoto M, Shibahara S, Fujita H, Igarashi K (2001) Heme mediates derepression of Maf recognition element through direct binding to transcription repressor Bach1. EMBO J 20:28352843. https://doi.org/10.1093/emboj/20.11.2835

24. Ogielska EM, Zagotta WN, Hoshi T, Heinemann SH, Haab J, Aldrich RW (1995) Cooperative subunit interactions in C-type inactivation of K channels. Biophys J 69:2449-2457. https://doi.org/ 10.1016/S0006-3495(95)80114-1

25. Oliver D, Lien CC, Soom M, Baukrowitz T, Jonas P, Fakler B (2004) Functional conversion between A-type and delayed rectifier $\mathrm{K}^{+}$channels by membrane lipids. Science 304:265-270. https://doi. org/10.1126/science.1094113

26. Padanilam BJ, Lu T, Hoshi T, Padanilam BA, Shibata EF, Lee HC (2002) Molecular determinants of intracellular $\mathrm{pH}$ modulation of human Kv1.4 N-type inactivation. Mol Pharmacol 62:127-134. https://doi.org/10.1124/mol.62.1.127

27. Pardo LA, Heinemann SH, Terlau H, Ludewig U, Lorra C, Pongs O, Stühmer W (1992) Extracellular $\mathrm{K}^{+}$specifically modulates a rat brain $\mathrm{K}^{+}$channel. Proc Natl Acad Sci U S A 89:2466-2470. https:// doi.org/10.1073/pnas.89.6.2466

28. Rettig J, Heinemann SH, Wunder F, Lorra C, Parcej DN, Dolly JO, Pongs O (1994) Inactivation properties of voltage-gated $\mathrm{K}^{+}$channels altered by presence of $\beta$-subunit. Nature 369:289-294. https:// doi.org/10.1038/369289a0

29. Ritter DM, Ho C, O'Leary ME, Covarrubias M (2012) Modulation of Kv3.4 channel N-type inactivation by protein kinase $\mathrm{C}$ shapes the action potential in dorsal root ganglion neurons. J Physiol 590: 145-161. https://doi.org/10.1113/jphysiol.2011.218560
30. Ritter DM, Zemel BM, Hala TJ, O'Leary ME, Lepore AC, Covarrubias M (2015) Dysregulation of Kv3.4 channels in dorsal root ganglia following spinal cord injury. J Neurosci 35:1260 1273. https://doi.org/10.1523/jneurosci.1594-14.2015

31. Roeper J, Lorra C, Pongs O (1997) Frequency-dependent inactivation of mammalian A-type $\mathrm{K}^{+}$channel $\mathrm{K}_{\mathrm{V}} 1.4$ regulated by $\mathrm{Ca}^{2+} /$ calmodulin-dependent protein kinase. J Neurosci 17:3379-3391

32. Ruppersberg JP, Stocker M, Pongs O, Heinemann SH, Frank R, Koenen M (1991) Regulation of fast inactivation of cloned mammalian $\mathrm{I}_{\mathrm{K}}(\mathrm{A})$ channels by cysteine oxidation. Nature 352:711-714. https://doi.org/10.1038/352711a0

33. Sahoo N, Schönherr R, Hoshi T, Heinemann SH (2012) Cysteines control the $\mathrm{N}$ - and $\mathrm{C}$-linker-dependent gating of $\mathrm{KCNH} 1$ potassium channels. Biochim Biophys Acta 1818:1187-1195. https://doi.org/ 10.1016/j.bbamem.2012.01.021

34. Sahoo N, Goradia N, Ohlenschläger O, Schönherr R, Friedrich M, Plass W, Kappl R, Hoshi T, Heinemann SH (2013) Heme impairs the ball-and-chain inactivation of potassium channels. Proc Natl Acad Sci U S A 110:E4036-E4044. https://doi.org/10.1073/pnas. 1313247110

35. Sheng M, Tsaur ML, Jan YN, Jan LY (1992) Subcellular segregation of two A-type $\mathrm{K}^{+}$channel proteins in rat central neurons. Neuron 9:271-284

36. Shimizu T, Lengalova A, Martinek V, Martinkova M (2019) Heme: emergent roles of heme in signal transduction, functional regulation and as catalytic centres. Chem Soc Rev 48:5624-5657. https://doi. org $/ 10.1039 / \mathrm{c} 9 \operatorname{cs} 00268 \mathrm{e}$

37. Tang XD, Xu R, Reynolds MF, Garcia ML, Heinemann SH, Hoshi $\mathrm{T}$ (2003) Haem can bind to and inhibit mammalian calciumdependent Slo1 BK channels. Nature 425:531-535. https://doi. org/10.1038/nature02003

38. Wissmann R, Bildl W, Oliver D, Beyermann M, Kalbitzer HR, Bentrop D, Fakler B (2003) Solution structure and function of the "tandem inactivation domain" of the neuronal A-type potassium channel Kv1.4. J Biol Chem 278:16142-16150. https://doi.org/ 10.1074/jbc.M210191200

39. Yang K, Coburger I, Langner JM, Peter N, Hoshi T, Schönherr R, Heinemann SH (2019) Modulation of $\mathrm{K}^{+}$channel N-type inactivation by sulfhydration through hydrogen sulfide and polysulfides. Pflügers Arch 471:557-571. https://doi.org/10.1007/s00424-0182233-x

Publisher's note Springer Nature remains neutral with regard to jurisdictional claims in published maps and institutional affiliations. 